\title{
L'archiviazione dei dati genetici a fini di giustizia penale: gli interessi in gioco, le prescrizioni europee, le soluzioni adottate dal legislatore italiano
}

Storage of genetic data for criminal justice purposes: interests at stake, European regulations, solutions adopted by Italian lawmakers

\begin{abstract}
Arquivamento de dados genéticos com finalidades penais: interesses em jogo, regulações europeias

e soluções adotadas pelo legislador italiano
\end{abstract}

Chiara Gabrielli ${ }^{1}$

Università degli Studi di Urbino Carlo Bo/Italia

chiara.gabrielli@uniurb.it

http://orcid.org/0000-003-4605-2319

\begin{abstract}
AвSTRACt: Dotarsi di un database dei dati genetici a fini di giustizia penale rappresenta per qualsiasi ordinamento una sfida ineludibile, ma di particolare delicatezza. Ineludibile, perché immagazzinare profili del dna appartenenti a una determinata platea soggettiva in vista della comparazione automatizzata mediante procedure informatiche significa mettere a disposizione degli inquirenti risorse di innegabile rilevanza probatoria. Particolarmente delicata, in quanto dalle scelte che governano acquisizione, conservazione e consultazione di dati geneticamente significativi dipende l'impatto che la "biologizzazione della sicurezza" è destinata a produrre sulla c.d. informational privacy, intesa come diritto dell'individuo al controllo delle informazioni riguardanti la propria sfera personale, tutelata dall'art. 8 della Convenzione europea per la salvaguardia dei diritti dell'uomo e delle libertà fondamentali. In Italia, la banca dati del dna è divenuta operativa soltanto di recente, al termine di un faticoso percorso legislativo. Il contributo si propone di
\end{abstract}

1 Ricercatrice di Diritto processuale penale. 
analizzare le scelte tecniche e valoriali operate dalla legge n. 85 del 2009 e dei provvedimenti di attuazione, verificandone la capacità di assicurare un bilanciamento tra gli interessi in contrasto conforme ai parametri di ragionevolezza e proporzionalità e la sintonia con le indicazioni della giurisprudenza della Corte europea dei diritti dell'uomo. Soltanto a queste condizioni il sacrificio richiesto alla "privacy genetica" per il perseguimento degli scopi di giustizia penale può risultare culturalmente e socialmente accettabile, oltre che giuridicamente legittimo. Non c'è dubbio, infatti, che la domanda collettiva di sicurezza sia divenuta progressivamente più insistente, anche per il diffondersi del fenomeno terroristico; altrettanto innegabilmente, però, si è acuita la sensibilità collettiva verso le differenti declinazioni della riservatezza personale, in special modo nei confronti di un patrimonio genetico ormai percepito come "marchio" dell'individualità soggettiva. Nessun ordinamento moderno, dunque, può sottrarsi al compito di rendere la tecnologia alleata della privacy tanto quanto della giustizia penale.

Parole-Chiave: Dati genetici; banca dati del dna; sicurezza collettiva; riservatezza; ingerenza nella vita privata e familiare.

ABSTRACT: For any legal system, having a genetic database for the purposes of criminal justice represents an unavoidable but particularly delicate challenge. Unavoidable, because storing DNA profiles that belong to a given subjective population for computer comparison means providing investigators with resources of undeniable probative value. Particularly delicate, as the choices that determine the acquisition, conservation and consultation of genetically significant data generate the impact of the "biologisation of security" on so-called informational privacy, namely the right of the individual to check information that regards his/ her personal sphere, defined by article 8 of the European Convention for the Protection of Human Rights and Fundamental Freedoms. In Italy, the DNA database has recently become operational, following a laborious legislative procedure. This contribution sets out to analyse the technical and value-related bases for law no. 85 of 2009 and the provisions for its introduction. It also proposes to assess this law's capacity to ensure an adequate balance between contrasting interests that keep within the parameters of reasonableness and proportionality, as well as being in congruence with the jurisprudence of the European Court of Human Rights. It is only on these conditions that the sacrifice required of "genetic privacy" for the pursuit of the aims of criminal justice could be deemed culturally 
and socially acceptable, as well as juridically legitimate. Indeed, there is no doubt that the collective demand for security has become progressively more insistent, also in view of the growth of terrorism. Just as undeniable, however, is the public's growing sensitivity towards the various aspects of personal confidentiality, especially regarding a genetic heritage that is now seen as a mark of subjective individuality. No modern law system can thus avoid the task of making technology an ally of privacy, especially in the ambit of criminal justice.

KEYWORDS: genetic data; genetic forensic database; public security; privacy; interference in private and family life.

Resumo: Criar um banco de dados genéticos com finalidades penais representa para qualquer ordenamento um desafio inevitável e, contemporaneamente, muito delicado. É inevitável porque armazenar perfis de DNA pertencentes a um determinado grupo de sujeitos para realizar uma comparação automatizada mediante procedimentos informáticos significa disponibilizar aos órgãos investigativos informações de inegável relevância probatória. Particularmente delicada pois em razão das escoIhas que governam a colheita, conservação e consulta de dados genéticos relevantes depende o impacto que a "biologização da segurança" finda por produzir em relação à denominada informational privacy, ou seja, o direito do indivíduo ao controle das informações relativas à própria esfera pessoal, tutelado pelo art. 8 da Convenção Europeia dos direitos humanos. Na Itália, o banco de dados do DNA tornou-se operativo somente recentemente, após um percurso legislativo demasiadamente tormentoso. Neste artigo serão analisadas as escolhas técnicas e valorativas efetuadas pela Lei n. 85 de 2009 e pelas regulamentações de atuação, verificando a sua capacidade de assegurar um balanceamento entre os interesses em jogo em contraste conforme os parâmetros de razoabilidade e proporcionalidade e a sintonia com as indicações da jurisprudência do Tribunal europeu dos direitos humanos. Somente se atendidas tais condições, o sacrifício imposto à "privacidade genética" para o alcance dos objetivos de justiça penal pode ser considerado culturalmente e socialmente aceitável, além de juridicamente legítimo. De fato, não há dúvidas de que o clamor coletivo por segurança se tornou progressivamente mais insistente, especialmente pela difusão do fenômeno do terrorismo. Não obstante, é também inegável que a sensibilidade coletiva se tornou mais atenta em relação às diferentes declinações na privacidade pessoal, e, em particular, ao patrimônio genético agora percebido como marca da individualidade subjetiva. Nenhum ordenamento moderno, portanto, pode subtrair-se 
à tarefa de tornar a tecnologia uma aliada da privacidade tanto quanto da justiça penal.

Palavras-chave: Dados genéticos; banco de dados de DNA; segurança coletiva; privacidade; ingerência na vida privada e familiar.

Sommario: 1. Una sfida impegnativa, ma non eludibile. 2. L'esperienza italiana. 3. Res conservate e presidi di sicurezza. 4. II perimetro soggettivo del database. 5. Le cautele da adottare nella fase di prelievo. 6. I tempi di conservazione: le scelte normative. 7. ... e gli aspetti da rimeditare. Bibliografia.

\section{UNA SFIDA IMPEGNATIVA, MA NON ELUDIBILE}

"Ogni criminale lascia una traccia di sé sulla scena del crimine", teorizzava già agli inizi del ' 900 il criminologo francese Edmond Locard, direttore a Lione del primo laboratorio di polizia scientifica, intuendo l'inevitabile interscambio che si realizza, in presenza di alcune condotte criminose, tra l'autore del reato, la vittima e il luogo dell'evento. Dalla traccia biologica lasciata da un soggetto è possibile estrarre un'impronta genetica, che lo connota in modo esclusivo: la rivoluzionaria scoperta fu compiuta nel 1984 da Alec J. Jeffreys, genetista dell'Università di Leicester. Dunque, quando si registra una corrispondenza tra la stringa del dna estratta dal campione biologico prelevato a un determinato soggetto e il profilo genetico ricavato da un reperto organico rinvenuto sulla scena del crimine, addosso alla vittima del reato, sulla superficie dell'arma del delitto, si può ragionevolmente ritenere che tale soggetto si sia recato in quel luogo, sia entrato in relazione con la persona offesa, sia stato a contatto con l'arma del delitto ${ }^{2}$. Il che non significa rispondere «all'ultima

2 «Una sola differenza è sufficiente per escludere che due profili vengano dalla stessa persona; se invece le sequenze sono sovrapponibili, si può concludere che risalgono ad un unico soggetto; concettualmente si tratta d'una valutazione probabilistica (infatti è necessario calcolare, attraverso modelli matematico-statistici, con quale frequenza determinati geni ricorrano nell'ambito della popolazione di riferimento); ma la probabilità può essere talmente alta da 
abduzione, quella che permette di attribuire il reato a un soggetto ${ }^{3}$, ma dimostrare una circostanza che potrebbe risultare risolutiva per gli esiti dell'accertamento penale.

Considerata la relativa facilità con cui nell'era dell'informatica i dati genetici possono essere gestiti e catalogati mediante software, non ha tardato a farsi strada nei diversi Paesi, a cominciare dal Regno Unito ${ }^{4}$, l'idea di immagazzinare preventivamente in una banca dati nazionale $\mathrm{i}$ profili del dna appartenenti a una "qualificata” platea soggettiva, così da rendere disponibili a fini di giustizia penale - «in modo continuativo e indipendente da questa o quella indagine, da questo o quel procedimento in corso» ${ }^{5}$ - informazioni rapidamente confrontabili, attraverso procedure di comparazione automatizzata.

Sul versante dell'identificazione personale, la corrispondenza riscontrata tra il profilo relativo a un indiziato la cui identità anagrafica sia incerta e uno dei profili custoditi nel database consentirà di stabilire le generalità esatte dell'interessato. Sul versante probatorio, il match

rasentare la certezza» (CAMON, Alberto, La disciplina delle indagini genetiche, in Cass. pen., 2014, p. 1427).

3 Così FASSONE, Elvio, Le scienze come ausilio nella ricerca del fatto e nel giudizio di valore, in DE CATALDO NEUBURGER, Luisa (a cura di), La prova scientifica nel processo penale, Cedam, 2007, p. 247, il quale esemplifica: «se la scienza dice che quella impronta appartiene a Tizio, questo ci autorizza a ritenere che Tizio ha toccato quell'oggetto, non che Tizio abbia commesso il furto in quell'appartamento, nel quale può avere avuto accesso per legittime ragioni. Così per la traccia rinvenuta, che, analizzata quanto al DNA, conduce a Caio». La prova del dna dovrebbe essere correttamente ritenuta «una prova indiziaria a matrice statistica», sintetizza LUPARIA, Luca, Dati genetici e cultura processuale: un futuro ancora da comporre, in MARAFIOTI, Luca, LUPARIA, Luca (a cura di), Banca dati del DNA e accertamento penale, Giuffrè, 2010 , p. 348, e subire «il filtro dei necessari riscontri e l'operatività della regola di giudizio dell'“oltre ogni ragionevole dubbio"» (PRESUTTI, Adonella, L'acquisizione forzosa dei dati genetici tra adempimenti internazionali e impegni costituzionali, in Riv. it. dir. proc. e pen., 2010, p. 548).

4 Paese in cui la banca dati dei profili del dna esiste già dal 1995.

5 GENNARI, Giuseppe, La istituzione della banca dati del Dna ad uso forense: dalla privacy alla sicurezza, in SCARCELLA, Alessio (a cura di), Prelievo del DNA e banca dati nazionale, Cedam, 2009, p. 71. Sui vantaggi apportati da tale archivio all'attività inquirente v. anche le riflessioni di ORLANDI, Renzo, PAPPALARDO, Giuseppe, L'indagine genetica nel processo penale germanico. Osservazioni su una recente riforma, in Dir. proc. pen., 1999, p. 767. 
registrato tra un profilo "anonimo" rinvenuto sul luogo del reato e uno dei profili presenti in archivio accrediterà come estremamente probabile il collegamento tra il soggetto cui questo appartiene e l'episodio criminoso; nel caso in cui si tratti della persona sottoposta alle indagini, l'esito del riscontro comparativo rafforzerà il compendio indiziario a suo carico, ferma restando l'esigenza di «inserire sempre la prova del DNA in un più ampio quadro critico di supporto e riscontro, onde evitare inammissibili errori» ${ }^{6}$; ove il profilo risulti appartenere ad un differente soggetto, allontanerà i sospetti dall'indagato e suggerirà nuove prospettive di investigazione da approfondire. Infine, qualora gli inquirenti stiano procedendo contro ignoti, l'abbinamento tra i profili farà finalmente emergere una direzione soggettiva di indagine.

Conservando nell'archivio anche i profili genetici "anonimi", estratti nel corso di un procedimento penale da reperti rinvenuti sulla scena del crimine, si schiudono ulteriori prospettive: inchieste penali rimaste senza esito potrebbero essere riaperte nel caso in cui, immettendo il profilo estratto dal campione di un certo soggetto nella banca dati, si registrasse una corrispondenza con uno dei profili "muti" che vi sono custoditi; spunti investigativi potrebbero emergere anche dal match tra due profili "anonimi": diversi episodi criminosi diverrebbero, infatti, plausibilmente attribuibili al medesimo autore.

Essendo impensabile che gli inquirenti rinuncino ad avvalersi delle preziose risorse offerte dalla genetica forense, quell'ordinamento che non si faccia carico di disciplinare l'acquisizione e la conservazione dei profili del dna a fini di giustizia penale mostrerebbe una preoccupante inconsapevolezza. Consegnare improvvidamente la gestione di tali fasi all'anarchia della prassi significherebbe, infatti, favorire disomogenee modalità di acquisizione di campioni e reperti biologici, differenti tecniche di analisi degli stessi ai fini della tipizzazione dei profili e standard di sicurezza dei dati non uniformi; ne risentirà, inevitabilmente, la possibilità di esercitare un controllo adeguato sia sull'affidabilità delle prime sia

6 MARAFIOTI, Luca, Le banche dati del dna. Una nuova frontiera investigativa nel trattato di Prüm, in MARAFIOTI, Luca-LUPARIA, Luca (a cura di), Banca dati del DNA e accertamento penale, Giuffrè, 2010, p. 8. 
sull'efficienza dei secondi'; d'altra parte, la frammentazione territoriale degli archivi permetterà unicamente una comparazione "parcellizzata" e quindi parziale, pregiudicando anche le chance di cooperazione giudiziaria con gli altri Stati.

Per queste ragioni, la creazione di un'anagrafe nazionale "centralizzata" dei dati genetici a scopi di giustizia penale, disciplinata da un preciso statuto giuridico e organizzata mediante le più efficaci strumentazioni tecnologiche, è compito al quale nessun ordinamento, a qualsiasi latitudine, sembra potersi sottrarre. Si tratta, intuibilmente, di una sfida di notevole complessità. Impone al legislatore di misurarsi con un contesto normativo tendenzialmente "multilivello", in cui convivono, al di là delle differenze geografiche, fonti internazionali, previsioni pattizie, prescrizioni costituzionali, disposizioni in tema di privacy, norme processuali. Presuppone, inoltre, il dominio di categorie e di nozioni appartenenti ai territori, meno familiari rispetto a quelli giuridici, della genetica forense e della tecnologia: adeguate conoscenze scientifiche, ricavate dai documenti elaborati dalle più accreditate organizzazioni di esperti della materia ${ }^{8}$, sono essenziali per distinguere quale res geneticamente rilevante (o sua porzione) sia necessario conservare a fini di identificazione e quale, invece, essendo superflua, non debba essere archiviata ${ }^{9}$; come pure, aggiornate nozioni di genetica forense sono indispensabili al legislatore per rendersi conto di quali ulteriori informazioni, non necessarie a fini identificativi, possa fornire la res

7 Aspetti problematici che non hanno impedito alla giurisprudenza di ritenere utilizzabile, «in mancanza della violazione di un divieto di legge, l'accertamento sull'identità dell'indagato compiuto mediante ricorso ai dati relativi al DNA contenuti in un archivio informatico che la polizia giudiziaria abbia istituito prescindendo dalle cautele previste dal codice della privacy» (Cass., sez. V, 5 febbraio 2007, Vulicevic ed al., in CED Cass., n. 235969).

8 Ad esempio, il documento "Dna Data management rewiew and recommendations” elaborato dall'ENFSI DNA Working Group, organizzazione internazionale che riunisce esperti di scienze forensi. Per una sintesi dei suoi contenuti, in rapporto alle scelte del legislatore italiano, v. LAGO, Giampietro, Banche dati DNA: raccomandazioni internazionali, studio comparato con la Legge 85/2009, in Giust. pen., 2010, p. 142 ss.

9 «Uno Stato democratico è anche quello che si caratterizza per sobrietà informativa», afferma condivisibilmente RODOTÀ, Stefano, Difendere $i$ cittadini dagli abusi della scienza, in La Repubblica, 6 gennaio 1999. 
custodita nel database, così da poter valutare il livello di protezione di cui la stessa deve essere proporzionalmente circondata.

Inoltre, si tratta di una sfida che nessun legislatore avveduto può ritenere di aver vinto in modo definitivo, una volta per tutte. Rispetto alle disposizioni che governano altri settori, la disciplina in questione va incontro fatalmente a un'obsolescenza più rapida; un legislatore accorto dovrebbe perciò mettere in conto periodiche "revisioni" dell'assetto normativo, così da adeguare strumenti e regole ai progressi sia della genetica forense (ad esempio, la messa a punto di più affidabili metodologie di analisi) sia della tecnologia (ad esempio, la sperimentazione di più sofisticate soluzioni informatiche, capaci di assicurare un incremento delle protezione contro illegittimi accessi all'archivio), come pure a non improbabili mutamenti della sensibilità collettiva.

Per tenere meglio il passo dell'evoluzione scientifica, la definizione degli aspetti squisitamente tecnici potrebbe essere affidata a fonti regolamentari, che si prestano ad interventi di modifica più agevoli rispetto alle norme di legge, perché sottratte al confronto parlamentare ${ }^{10}$. I nodi valoriali della materia vanno tuttavia sciolti in sede legislativa; ben lontane dal rappresentare questioni di rilevanza settoriale, le scelte che governano acquisizione, conservazione e consultazione dei dati geneticamente significativi declinano lo storico antagonismo tra sicurezza collettiva e libertà individuali ${ }^{11}$, definendo l'impatto che la «biologizzazione della sicurezza» ${ }^{12}$ è destinata a produrre sulla c.d.

10 In argomento v. SIGNORATO, Silvia, Il trattamento dei dati personali per fini di prevenzione e repressione penale, in Riv. dir. proc., 2015, p. 1492 ss.

11 Ne appariva consapevole, già agli inizi degli anni Novanta, il Comitato dei ministri del Consiglio d'Europa: nel Preambolo della Raccomandazione (92)1 sottolineava $\mathrm{i}$ «benefici apportati alla giustizia penale dalle tecniche di analisi del Dna», ma avvertiva lucidamente, altresì, l'esigenza che il loro impiego tenesse «pienamente conto di principi fondamentali quali la dignità propria di ciascuna persona ed il rispetto del corpo umano, il diritto di difesa ed il principio di proporzionalità». Sul «pionieristico (...) apporto del Consiglio d'Europa in tema di tutela dei dati personali, prima, e della prova genetica e banche dati del DNA, poi» v. ALLEGREZZA, Silvia, Prova scientifica e dimensione europea, in CANZIO, Giovanni, LUPARIA, Luca (a cura di), Prova scientifica e processo penale, Giuffrè, 2018, p. 125.

12 L'efficace espressione indica «una politica pubblica che fonda il suo operare sull'analisi del DNA» (SCAFFARDI, Lucia, Giustizia genetica e tutela della persona, Cedam, 2017, p. 256). 
informational privacy, intesa come diritto dell'individuo al controllo delle informazioni riguardanti la propria sfera personale.

Dalla capacità dell'ordinamento di contenere tale impatto entro limiti ragionevoli, peraltro, dipenderà anche la possibilità che il sacrificio richiesto alla "privacy genetica" a scopi penali risulti culturalmente e socialmente accettabile, oltre che legittimo. Non c'è dubbio che la domanda collettiva di sicurezza sia divenuta oggi più insistente, anche per il diffondersi del fenomeno terroristico; altrettanto innegabilmente, però, si è acuita la sensibilità verso le variegate espressioni della riservatezza personale, in speciale modo nei confronti di un patrimonio genetico ormai percepito come «il marchio dell'individualità soggettiva» ${ }^{13}$. Al soddisfacimento di entrambe queste istanze - di sicurezza collettiva e di sicurezza dei dati individuali - può certamente contribuire l'evoluzione della tecnologia, alleata preziosa della riservatezza non meno che della giustizia penale. Un ordinamento che opportunamente si avvale di sofisticati software che consentono la comparazione automatizzata di un profilo genetico anonimo con la totalità dei profili immessi nella banca dati, facendone emergere l'eventuale corrispondenza in tempi estremamente rapidi, dovrà anche farsi carico di organizzare la "messa in sicurezza" dei dati genetici, ricorrendo alle più avanzate risorse tecnologiche e informatiche disponibili.

\section{L'ESPERIENZA ITALIANA}

Da tempo, per gli ordinamenti dei Paesi aderenti all'Unione europea, dotarsi di strutture idonee ad archiviare dati genetici rappresenta un obbligo giuridicamente ineludibile. Se la Risoluzione del 9 giugno 1997 sullo scambio dei risultati di analisi del dna invitava gli Stati membri dell'Unione europea «a prevedere la costituzione di banche dati nazionali», auspicabilmente caratterizzate da standard uniformi, la Decisione 2008/615/GAI del 23 giugno 2008, recependo i contenuti del

13 DAL MIGLIO, Chiara, GENTILOMO, Andrea, PICCININI Andrea, D’AURIA, Luca, Dal prelievo coattivo alla banca dati dei profili genetici:l'ennesima incompiuta, in Riv. it. dir. med. leg., 2007, p. 85. 
Trattato di Prüm ${ }^{14}$, li obbligava a «creare e gestire schedari nazionali di analisi del DNA per le indagini penali» e ad assicurare reciproci «diritti di accesso» agli stessi, mediante procedure automatizzate di consultazione e di raffronto attivabili dai punti di contatto nazionali dei Paesi membri. Adempimenti necessari a rafforzare quello scambio di informazioni genetiche tra Stati che la c.d. decisione Prüm del 2008 individua come tassello di «fondamentale importanza» per una efficace cooperazione internazionale in materia di giustizia penale.

Pur avendo espresso già nel 2006, tramite il Ministro dell'interno, l'intenzione di aderire al Trattato di Prüm, l'Italia ha recepito tali sollecitazioni con sensibile ritardo: si è dovuto attendere fino a giugno 2009 perché fosse approvata la «prima legge organica sulla acquisizione e il trattamento della bioinformazione genetica a fini forensi» ${ }^{15}$. Il protrarsi dell'inerzia legislativa in materia aveva suscitato l'intervento preoccupato del Garante per la protezione dei dati personali, convinto dell'«urgenza di disciplinare organicamente», con riguardo all'acquisizione dei dati genetici per finalità di accertamento e di repressione dei reati, «competenze, procedure e modalità di tutela degli interessati» ${ }^{16}$. Sullo sfondo si avvertiva la preoccupazione che la perdurante lacuna normativa avrebbe non solo compromesso le chance di cooperazione giudiziaria con gli altri Stati, ma anche incentivato il diffondersi di archivi "artigianali", allestiti dalle forze di polizia al di fuori di qualsiasi cornice normativa ${ }^{17}$ e perciò caratterizzati «da statuto giuridico incerto e da garanzie a contorni sfumati» ${ }^{18}$.

14 Stipulato il 27 maggio 2005 tra Belgio, Germania, Spagna, Francia, Lussemburgo, Paesi Bassi e Austria.

15 GENNARI, Giuseppe, Bioinformazione e indagini penali: la l. n. 85 del 30 giugno 2009, in Resp. civ. e prev., 2009, p. 2630.

16 Segnalazione al Parlamento e al Governo sulla disciplina delle banche dati del dna a fini di giustizia, 19 settembre 2007, in Bollettino n. 86 del settembre 2007.

17 La realtà di un archivio di profili genetici presso il Reparto investigazioni scientifiche (RIS) di Parma era emersa nel corso di un'inchiesta penale per furto, rendendo necessario l'intervento del Garante per la protezione dei dati personali al fine di imporre minime misure di sicurezza. Per una dettagliata descrizione della vicenda v. GENNARI, Giuseppe, Genetica forense e codice della privacy: riflessioni su vecchie e nuove banche dati, in Resp. civ. e prev., 2011, p. 1184 ss.

18 DAL MigliO, Chiara, GENTILOMO, Andrea, PICCININI, Andrea, D'AURIA, Luca, Dal prelievo coattivo alla banca dati dei profili genetici: l'ennesima 
La legge n. 85 del 2009 di ratifica del Trattato di Prüm ha istituito la banca dati nazionale del dna e il laboratorio centrale, disciplinandone la fisionomia; numerosi aspetti, decisivi per il funzionamento delle due strutture, erano tuttavia demandati a successivi regolamenti di attuazione ${ }^{19}$.

La gestazione normativa si è rivelata molto più lunga di quanto pronosticato dal legislatore, forse con eccessivo ottimismo ${ }^{20}$ : il regolamento attuativo, contenente «indicazioni cogenti in termini di qualità analitica, tracciabilità, interpretazione» ${ }^{21}$, ha visto la luce soltanto nel $2016^{22}$, rinviando a sua volta, per diverse questioni operative, ad ulteriori provvedimenti, che il Ministro dell'interno avrebbe dovuto adottare di

incompiuta, cit., p. 86. Rileva tuttavia «l'ambiguità» della disciplina del 2009, «con riferimento alla sorte degli archivi genetici non ufficiali che sembra siano destinati a convivere con la Banca nazionale del dna», FELICIONI, Paola, DNA e Banche dati europee, in AA. VV., Investigazioni e prove transnazionali, Giuffrè, 2017, p. 200.

19 Soluzione non implausibile nell'ottica di facilitare l'adeguamento all'evoluzione della genetica forense, rendendo più agevoli le «modifiche delle norme regolamentari che dovessero risultare non in linea con i nuovi standard tecnico-scientifici» (SCOLLO, Giancarlo, La disciplina attuativa della banca dati del dna e del laboratorio centrale, in MARAFIOTI, Luca, LUPARIA, Luca (a cura di), Banca dati del DNA e accertamento penale, Giuffrè, 2010, p. 165). Perplessità sul rinvio alla fonte regolamentare sono espresse dalla dottrina giuridica: per tutti, ORLANDI, Renzo, La riforma del processo penale fra correzioni strutturali e tutela "progressiva" dei diritti fondamentali, in Riv. it. dir. proc. pen., 2014, p. 1155; SANTOSUOSSO, Amedeo, COLUSSI, Ilaria Anna, La banca dati del DNA: questioni in tema di alimentazione, trattamento e accesso, presupposti, cancellazione e tempi di conservazione (artt. 5-15 l. n. 85/09), in Pol. dir., 2011, p. 457.

20 La disciplina di attuazione avrebbe dovuto essere emanata entro quattro mesi dall'entrata in vigore della legge n. 85 del 2009, su proposta del Ministro della giustizia e del Ministro dell'interno, e previa interlocuzione con il Garante per la protezione dei dati personali e il presidente del Comitato nazionale per la biosicurezza e le biotecnologie, chiamati a fornire un parere sul relativo schema.

21 RICCI, Ugo, Un lampo di consapevolezza nella normativa italiana: il DNA oltre la suggestione e il mito, in Dir. pen. proc., 2016, p. 753.

22 Si tratta del Regolamento recante disposizioni di attuazione della legge 30 giugno 2009, n. 85, concernente l'istituzione della banca dati nazionale del DNA e del laboratorio centrale per la banca dati nazionale del DNA, ai sensi dell'articolo 16 della legge n. 85 del 2009, adottato con d.P.R. 7 aprile 2016, n. 87, in G.U., 26 maggio 2016, n. 122. 
concerto con il Ministro della giustizia ${ }^{23}$. Ora che il "mosaico normativo" si è finalmente completato, consentendo alla struttura di divenire operativa ${ }^{24}$, è possibile analizzarne le opzioni qualificanti in rapporto ai principali plessi problematici posti dall'accantonamento dei dati genetici.

\section{RES CONSERVATE E PRESIDI DI SICUREZZA}

Campione biologico e profilo del dna si distinguono per un differente potenziale informativo, che si riflette sulle implicazioni connesse alla loro conservazione ${ }^{25}$. Essendo un «codice alfanumerico» relativo alla «parte non codificante di un campione di dna umano analizzato ${ }^{26}$, il profilo del dna non consente di ricostruire le

23 Con decreto del Ministro dell'interno del 12 maggio 2017 sono state definite le modalità di cancellazione dei profili del dna, di distruzione dei campioni biologici, di immissione e aggiornamento dei dati necessari ai fini della determinazione dei tempi di conservazione dei medesimi profili del dna; con decreto del Ministro dell'interno dell' 8 novembre 2016 sono state disciplinate le «procedure per il trattamento dei dati, da parte della banca dati del DNA e del laboratorio centrale per la banca dati nazionale del DNA, e per la trasmissione del profilo del DNA da parte dei laboratori di istituzioni di elevata specializzazione, in attuazione degli articoli 3, 4 e 6 del decreto del Presidente della Repubblica 7 aprile 2016, n. 87».

Un primo bilancio dei risultati finora ottenuti e dei progressi nell'implementazione della struttura si rinviene nell'intervista di Giusi Fasano a Renato Biondo, dirigente della Polizia di Stato e direttore della banca dati nazionale del dna (Quella banca dati di pochi DNA, in Corriere della Sera, 26 aprile 2019).

Sulla differenza tra la conservazione delle impronte digitali da un lato, dei campioni di materiale biologico e dei profili genetici dall'altro, in conseguenza delle maggiori potenzialità informative proprie di queste ultime due categorie di dati, v. Corte eur. dir. uomo, 7 dicembre 2006, Van der Velden c. Paesi Bassi. Sul maggiore "grado di criticità» della conservazione dei campioni rispetto al «trattamento dei profili» v. le osservazioni di COCITO, Andrea, Parametri internazionali e affidabilità dei laboratori nelle analisi dei reperti e campioni, in MARAFIOTI, Luca, LUPARIA, Luca (a cura di), Banca dati del DNA e accertamento penale, Giuffrè, 2010, p. 99.

La definizione contenuta nell'art. 2 lett. $v$ ) d.P.R. n. 87 del 2016 ricalca quella formulata dall'art. 2 lett. c) della Decisione 2008/616/GAI adottata il 23 giugno 2008 dal Consiglio dell'Unione europea, perfezionando così la meno completa previsione dell'art. 11 comma 3 legge n. 85 del 2009 («i sistemi di analisi sono applicati esclusivamente alle sequenze del DNA che non consentono la identificazione delle patologie da cui può essere affetto l'interessato»). 
caratteristiche fisiche del soggetto cui appartiene, ad eccezione del sesso, né i suoi tratti comportamentali ${ }^{27}$. Il campione biologico possiede, invece, potenzialità informative che oltrepassano quelle legate all'identificazione, evidenziando, ad esempio, patologie, esistenti o non ancora insorte, con conseguenti pericoli, nel caso di un'incontrollata divulgazione, di discriminazioni sul piano sociale ed economico, come pure di pregiudizi alla vita lavorativa e alle relazioni interpersonali ${ }^{28}$.

In considerazione di attitudini informative così marcate, la scelta legislativa di conservare anche i campioni biologici, diversamente da quanto avviene in altri ordinamenti ${ }^{29}$, ha suscitato perplessità; se per qualcuno il loro "stoccaggio" si può spiegare con la «possibilità di effettuare nuove analisi, magari a richiesta della difesa ed in considerazione dei progressi della scienza» ${ }^{30}$, secondo altri comporta «un rischio di violazione

27 RICCI, Ugo, PREVIDERÈ, Carlo, FATTORINI, Paolo, CORRADI, Fabio, La prova del dna per la ricerca della verità, Giuffrè, 2006, p. 30 ss. Peraltro, la valutazione delle attitudini informative degli stessi profili non è concetto "statico": come ricordato dal Garante europeo della protezione dei dati nel Parere del 21 luglio 2007, «occorre tener conto anche dei progressi scientifici: quello che in un dato momento è considerato un profilo di DNA "innocuo", potrebbe rivelare successivamente molte più informazioni di quanto non sia prevedibile e necessario». Come osserva SALSI, Giancarlo, La Banca Dati del DNA. Indagini genetiche e problematiche giuridiche, Clueb, 2012, p. 155, «quelle che definiamo oggi regioni non codificanti lo sono solamente nella misura in cui non siamo ancora riusciti a decifrarle».

28 «Il profilo genetico esprime una quantità di informazioni molto ridotta rispetto a quella ricavabile da un campione biologico», il quale «consente di ottenere ampie conoscenze su di una persona in punto di malattie e di caratteristiche ereditarie» (TONINI, Paolo, Accertamento del fatto e informazioni genetiche: un difficile bilanciamento, in Dir. pen. proc. - Speciale Banche dati, 2009, p. 3 ss.); al riguardo v. anche FANUELE, Chiara, Conservazione dei dati genetici e privacy: modelli stranieri e peculiarità italiane, in Dir. pen. e proc., 2011, p. 120.

29 Alcuni Paesi (come Portogallo, Spagna, Belgio, Germania, Svizzera, Norvegia) hanno previsto l'immediata distruzione del campione a seguito delle analisi necessarie a ricavare il profilo genetico. In questo senso si è orientato anche il Regno Unito, a seguito dell'approvazione del Protection of Freedom Act del 2012; la regola generale prevede la distruzione del campione entro sei mesi dall'estrazione del profilo, ma sono contemplate eccezioni che permettono la conservazione per un periodo più lungo.

30 FELICIONI, Paola, Il regolamento di attuazione della Banca dati nazionale del dna: scienza e diritto si incontrano, in Dir. pen. proc., 2016, p. 712. Per alcuni 
dei diritti individuali troppo elevato e non giustificato» ${ }^{31}$. Consapevole di dover fronteggiare questo genere di rilievi, il legislatore del 2009 ha affrontato con scrupolo la questione della "messa in sicurezza" dei dati custoditi (campioni e profili), apprestando presidi normativi, accorgimenti logicistici e cautele ad elevato coefficiente tecnologico.

L'incipit dell'art. 5 legge n. 85 del 2009 individua la finalità dell'istituzione della banca dati nazionale del dna nel «facilitare l'identificazione degli autori dei delitti», implicitamente escludendo che vi sia spazio tanto per l'acquisizione di dati eccedenti rispetto a questo scopo, quanto per ulteriori legittimi impieghi di profili e di campioni. L'indicazione teleologica trova conferma nell'art. 12 legge n. 85 del 2009, disposizione che ammette l'accesso ai dati conservati nella banca dati del dna e nel laboratorio centrale «esclusivamente per fini di identificazione personale»; quanto alle «finalità di collaborazione internazionale di polizia» evocate dalla medesima norma, non vanno intese come obiettivi diversi e aggiuntivi, ma, per coerenza, devono anch'esse limitarsi all'esclusivo scopo identificativo, sollecitato dalle autorità inquirenti di altri Stati. Significativamente, però, i presupposti per avviare la consultazione sono diversi a seconda che si tratti della banca dati in cui sono archiviati i profili del dna o del laboratorio centrale nel quale sono conservati i campioni biologici: nel primo caso, la polizia giudiziaria può sollecitarla autonomamente, nel secondo deve munirsi dell'autorizzazione dell'autorità giudiziaria $^{32}$. In ogni caso, le richieste di consultazione provenienti dalle

esempi dell'utilità di conservare anche la conservazione del materiale cellulare v. LAGO, Giampietro, Banche dati DNA: raccomandazioni internazionali, studio comparato con la Legge 85/2009, cit., p. 150.

31 Così MONTI, Andrea, Conservazione dei campioni biologici e tutela dei diritti fondamentali della persona, in MARAFIOTI, Luca, LUPARIA, Luca (a cura di), Banca dati del DNA e accertamento penale, Giuffrè, 2010, p. 55, sottolineando che «il campione biologico contiene tutta l'informazione: finché c'è una provetta in qualche laboratorio o deposito con una parte di mio materiale biologico, da quel campione è possibile fare una qualsiasi analisi, anche di tipo diagnostico» (p. 55, nota 1 ).

32 Sulla perimetrazione delle nozioni di polizia giudiziaria e autorità giudiziaria v. LAGO, Giampietro, Il trattamento dei dati e dei campioni biologici: la banca dati nazionale del DNA e il bilanciamento tra le ragioni di giustizia e la tutela della privacy, in SCARCELLA, Alessio (a cura di), Prelievo del DNA e banca dati nazionale, Cedam, 2009, p. 120 ss. 
forze di polizia vanno motivate in relazione al procedimento penale in cui è emersa l'esigenza del raffronto ${ }^{33}$.

Dall'impianto legislativo e dalla disciplina di attuazione, chiamata alla messa a punto dei dettagli tecnici, emergono due apprezzabili direttive. Rispetto agli accessi e alla natura delle operazioni compiute va assicurata la massima trasparenza, mediante l'identificazione di chiunque faccia ingresso fisicamente nei luoghi di conservazione e telematicamente nel database ${ }^{34}$, come pure attraverso la registrazione di ogni attività ingresso, consultazione, aggiornamento - che l'operatore ha compiuto e la conservazione delle relative registrazioni. Rispetto ai campioni biologici, ai profili del dna e alle generalità anagrafiche dei soggetti ai quali essi appartengono va garantita, al contrario, la massima inaccessibilità. Obiettivo al quale è rivolto più di un accorgimento. Anzitutto, profili e campioni sono conservati e gestiti in strutture distinte sul piano logistico e funzionale ${ }^{35}$ : soluzione impegnativa, perché richiede al legislatore di regolamentare e controllare scrupolosamente il flusso di dati dall'una

33 Una delicata valutazione alla quale è chiamato un ordinamento che si doti di una banca dati del dna attiene alle prerogative da riconoscere al difensore. Il dato normativo dell'art. 12 legge n. 85 del 2009 omette al riguardo qualsiasi riferimento rispetto alle chance del medesimo di interrogare l'archivio. Parte della dottrina ritiene che tale silenzio possa essere superato riconoscendo al difensore «il potere di chiedere al pubblico ministero l'autorizzazione all'esame presso la Banca dati e, se la pubblica accusa rigetta la richiesta, il difensore può proporre ricorso al giudice, al quale spetta di decidere» (TONINI, Paolo, Informazioni genetiche e processo penale ad un anno dalla legge, in Dir. pen. proc., 2010, p. 886). Giudica tale lettura difficilmente praticabile CAMON, Alberto, La disciplina delle indagini genetiche, cit., p. 1445: dai lavori preparatori emerge che «non c'è una lacuna, suscettibile di essere colmata con l'analogia», e che «il difensore non è stato dimenticato, bensì volutamente estromesso».

34 Nel Parere adottato il 28 luglio 2016 il Garante per la protezione dei dati personali aveva espresso l'esigenza che fossero apprestate misure di sicurezza a protezione delle aree di pertinenza della banca dati e del laboratorio centrale, sollecitando, tra l'altro, «ulteriori specificazioni (...) con riguardo a quali informazioni relative agli accessi fisici alle predette aree» sarebbero state registrate, «nonché ai tempi e alle modalità di conservazione».

35 Una scelta analoga è stata compiuta dall'ordinamento francese, che distingue la banca dati, in cui si conservano i profili genetici, dal Service Central de Préservation des Prélèvements Biologiques, dove viene conservato il materiale biologico. 
all'altra struttura ${ }^{36}$, ma necessaria ad impedire quell'incrocio di dati che permetterebbe di ricavare «una quantità incontrollata di informazioni relative a un determinato soggetto», comportando un «rischio elevato di violazione della privacy» ${ }^{37}$. Conservare i profili genetici e operarne il raffronto compete alla banca dati nazionale del dna istituita presso il Dipartimento della pubblica sicurezza del Ministero degli interni: a dispetto della sua denominazione, si tratta di un database informatico puro, che «contiene soltanto informazioni digitalizzate» ${ }^{38}$. Tipizzare $\mathrm{i}$ profili genetici dai campioni biologici e provvedere alla conservazione di questi ultimi spetta, invece, al laboratorio centrale collocato presso il Ministero della giustizia, che è la vera biobanca. Entrambe queste strutture sono sottoposte a forme di sorveglianza: il controllo sulla banca dati è, comprensibilmente, affidato al Garante per la protezione dei dati personali; alla supervisione operativa sul laboratorio deve provvedere il Comitato nazionale per la biosicurezza, le biotecnologie e le scienze della vita, mentre al Garante, suscitando qualche perplessità in dottrina ${ }^{39}$, è assegnato esclusivamente un compito consultivo rispetto alle verifiche che il Comitato deve eseguire presso il laboratorio.

Ambedue gli archivi, inoltre, contengono dati anonimizzati: per espressa prescrizione normativa, profili e campioni non devono essere contraddistinti da informazioni che consentano «l'identificazione diretta del soggetto cui sono riferiti» (art. 12 legge n. 85 del 2009) ${ }^{40}$.

36 Sul punto v. CALIFANO, Licia, Il trattamento dei dati genetici: finalità di ricerca, esigenze di sicurezza e diritto alla protezione dei dati personali, in Cultura giuridica e diritto vivente, 2017, n. 4, p. 7.

37 COLOMBO, Eleonora, Il nuovo regolamento per l'istituzione della banca dati nazionale del dna: commento a prima lettura e confronto con le disposizioni di altri Stati UE, in Cass. pen., 2016, p. 4617.

38 MONTI, Andrea, Ambiguità semantiche, finalità dei trattamenti e limiti operativi della genetic evidence, in MARAFIOTI, Luca, LUPARIA, Luca (a cura di), Banca dati del DNA e accertamento penale, Giuffrè, 2010, p. 34.

39 COLAIACOVO, Cinzia, Competenza del Garante per la protezione dei dati personali sull'applicazione del Trattato di Prüm, in SCARCELLA, Alessio (a cura di), Prelievo del DNA e banca dati nazionale, Cedam, 2009, p. 189.

40 La protezione delle informazioni è rafforzata dall'obbligo del segreto sugli atti, i dati, le informazioni di cui il personale addetto alla banca dati e al laboratorio sia venuto a conoscenza a causa dell'esercizio delle funzioni e presidiata penalmente dalla fattispecie incriminatrice che punisce il pubblico 
Ogni soggetto "censito" è contraddistinto da una coppia di valori: «un numero identificativo univoco» viene generato al momento del prelievo dal sistema AFIS - che acquisisce e gestisce le impronte digitali - ed è «associato al suo profilo del dna ${ }^{41}$. Soltanto nel caso in cui si registri una corrispondenza tra il profilo "anonimo" e uno di quelli conservati nella banca dati del dna sarà consentito risalire all'identità anagrafica del soggetto al quale appartiene, dato da comunicare agli organi inquirenti che hanno richiesto l'esplorazione. Decodificare il c.d. codice prelievo ossia la stringa identificativa assegnata dal sistema AFIS al momento in cui il relativo campione è stato prelevato - non compete, tuttavia, agli operatori che si occupano di implementare e di gestire la banca dati; per evitare una concentrazione di competenze, pericolosa per la riservatezza, il decisivo passaggio finale è affidato al personale in servizio presso l'AFIS, al quale, per contro, ancora nell'ottica apprezzabile di evitare pericolosi incroci, è vietato accedere direttamente ai sistemi informativi della banca dati del dna e del laboratorio centrale ${ }^{42}$.

ufficiale che, anche colposamente, comunica o fa uso di quei dati e di quelle informazioni «in violazione delle disposizioni del capo II della legge n. 85 del 2009 o al di fuori di fini previsti» dal medesimo.

41 Spiega BIONDO, Renato, La Banca dati nazionale dna italiana, in Riv. it. med. leg., 2016, p. 217.

42 Lo sforzo legislativo per assicurare, ricorrendo a risorse tecnologicamente avanzate, la "messa in sicurezza" delle informazioni genetiche custodite nel laboratorio centrale e nella banca dati nazionale del dna mette in risalto l'inadeguatezza della disciplina del codice di rito penale quando il prelievo di materiale biologico avvenga nel corso del procedimento penale, ai fini di una perizia o di una consulenza tecnica (artt. 224-bis e 359-bis c.p.p.). Rispetto ai campioni biologici, emergono dal dato codicistico "spazi" per la conservazione, fino alla «definizione del procedimento con decreto di archiviazione» o alla pronuncia di una «sentenza non più soggetta ad impugnazione», provvedimenti ai quali consegue l'obbligo di procedere alla distruzione degli stessi. Quanto alla conservazione, tuttavia, mancano nell'art. 72-quater disp. att. c.p.p. indicazioni logistiche: taluno ritiene che competa alla cancelleria individuare un luogo adeguato, altri identificano tale luogo nel laboratorio in cui è avvenuta la tipizzazione dei profili, altri ancora affidano la conservazione del campione al perito; in mancanza di presidi normativamente imposti, nessuno degli scenari prefigurabili in via interpretativa appare tranquillizzante sul piano della riservatezza. Altrettanto sorprendentemente, il legislatore del 2009 si è disinteressato della sorte dei relativi profili. Un riferimento ai profili genetici ricavati dai campioni biologici prelevati nel corso del procedimento penale compare oggi nel d.P.R. n. 87 del 2016, il cui art. 35 prevede che 


\section{IL PERIMETRO SOgGetTIVO DEL DATABASE}

Nel dettare le coordinate dell'“anagrafe genetica”, un legislatore che, avvalendosi delle più sofisticate strumentazioni tecnologiche, sia in grado di "blindare" $\mathrm{i}$ dati acquisiti potrebbe essere orientato a privilegiare soluzioni che ne massimizzino l'efficienza informativa a scopi di giustizia penale ${ }^{43}$. Si potrebbe ritenere, in altri termini, che standard più elevati di sicurezza autorizzino una maggiore estensione del patrimonio informativo custodito nel database, sul presupposto che, una volta efficacemente neutralizzati i rischi di indebiti "trattamenti" dei dati, non sarebbero prefigurabili ulteriori controindicazioni "da conservazione" ${ }^{44}$.

vengano inseriti nella banca dati del dna anche i profili ricavati da «campioni biologici di soggetti che al momento del prelievo rientravano nelle previsioni dell'articolo 9 della legge acquisiti nel corso di procedimenti penali anteriormente alla data di entrata in funzione della banca dati». Se si intendeva sopperire alla predetta lacuna legislativa, si è proceduto in modo piuttosto maldestro. Non solo perché ad estendere ai profili ricavati dai campioni biologici l'immissione nella banca dati del dna che l'art. 10 legge n. 85 del 2009 limitava ai profili estratti dai reperti biologici è un regolamento di attuazione, dunque una fonte normativa di rango subordinato, ma anche perché quest'ultimo si occupa dei soli profili acquisiti nel procedimento penale dai campioni prelevati alle categorie individuate dall'art. 9 legge n. 85 del 2009. Per tutti gli altri soggetti che abbiano subito il prelievo a fini investigativi o probatori la collocazione del relativo profilo continua dunque a risultare imprecisata. La sede più plausibile, secondo la dottrina, è rappresentata dal fascicolo processuale in cui il profilo è inserito (TONINI, Paolo, Manuale di procedura penale, Giuffrè, 2018, p. 600), ma dal punto di vista della "messa in sicurezza" dei dati in questione la soluzione non può che apparire insoddisfacente.

In questa direzione si era orientato in passato il Regno Unito, realizzando una «archiviazione dei dati genetici di tipo cosiddetto "pangenetico" o universale, tale da prevedere l'inserimento del maggior numero di dati acquisibili» (SCAFFARDI, Lucia, Giustizia genetica e tutela della persona, cit., p. 84).

«A properly constructed universal DNA database would pose only a minimal invasion of privacy. In return, it would decrease crime, reverse and prevent false conviction, make investigations more effective and efficient, and protect against far more invasive investigative techniques. A universal DNA database should be viewed as a way to protect ourselves and others, not as a "Big Brother" invasion of privacy», ritiene DEDRICKSON, Kristen, Universal DNA databases: a way to improve privacy?, in Journal of Law and the Biosciences, 2017, p. 647. Sui vantaggi di un «universal genetic forensic database» cfr. HAZEL, James, CLAYTON, Ellen, MALIN, Bradley, SLOBOGIN, Christopher, Is it time for a universal genetic forensic database?, in Science, 23 novembre 2018, p. 898 ss. 
Per gli Stati aderenti alla Convenzione europea per la salvaguardia dei diritti dell'uomo e delle libertà fondamentali percorrere questa strada significherebbe esporsi alle probabili censure della Corte di Strasburgo ${ }^{45}$. Stando alla sua consolidata elaborazione, infatti, la conservazione dei dati genetici da parte di un'autorità pubblica integra un'ingerenza nel diritto al rispetto della vita privata e familiare ${ }^{46}$ tutelato dall'art. 8 C.e.d.u., diritto nella cui poliedrica nozione i giudici europei ricomprendono anche gli aspetti legati all'identificazione personale e all'appartenenza, ricostruibile per via genetica, a un gruppo familiare ${ }^{47}$.

Tale ingerenza appare tollerabile solo a condizione di soddisfare $\mathrm{i}$ requisiti previsti dall'art. 8 \& 2 C.e.d.u.: oltre ad essere «prevista dalla legge», l'intromissione deve risultare «in una società democratica (...) necessaria» per il raggiungimento degli scopi individuati dalla norma in questione, tra cui figurano la sicurezza nazionale, la pubblica sicurezza, la difesa dell'ordine e la prevenzione dei reati. Anche là dove si riuscisse a garantire un livello molto elevato di protezione alle informazioni raccolte nella banca dati, dunque, nella prospettiva della Corte europea dei diritti dell'uomo la tutela della vita privata e familiare risulterebbe «indebolita in modo inaccettabile» in assenza di un «attento bilanciamento tra i vantaggi che possono derivare» alla giustizia penale dalla disponibilità dei dati genetici dei consociati e la tutela dei «fondamentali interessi che sono collegati al rispetto della vita privata» ${ }^{48}$.

45 Scarsamente propensa ad affidare «alla completa discrezionalità dei singoli Paesi i criteri di ingresso e di uscita dalla banca dati genetica», osserva SELLAROLI, Valentina, Il "caso S. e Marper" e la Corte europea: il DNA e il bilanciamento tra opposte esigenze in una società democratica, in Leg. pen., 2009, p. 646.

46 Più in generale, per la Corte di Strasburgo la conservazione di qualsiasi dato relativo alla vita privata di un soggetto costituisce di per sé un'ingerenza ai sensi dell'art. 8 C.e.d.u.: per tutti v. Corte eur. dir. uomo, 26 marzo 1987, Leander c. Svezia, § 48. Ciò indipendentemente dal fatto che tali dati siano effettivamente utilizzati, in quanto l'ingerenza nella vita privata si concretizza al momento della memorizzazione: così Corte eur. dir. uomo, 16 febbraio 2000, Amann c. Svizzera, § 69.

47 Sulla capacità dimostrata dalla Corte di Strasburgo di utilizzare l'art. 8 C.e.d.u. come «baluardo contro forme di intrusione legate all'uso di tecnologie» avanzate, e, più in generale, di «estrapolare dalle scarne previsioni della Convenzione un sistema di regole e principi all'avanguardia» v. ALLEGREZZA, Silvia, Prova scientifica e dimensione europea, cit., p. 127.

48 Corte eur. dir. uomo, 4 dicembre 2008, S. e Marper c. Regno Unito, § 112. 
Per quanto il dettato della Convenzione europea dei diritti dell'uomo lasci al legislatore nazionale margini non trascurabili di apprezzamento, il concetto di "necessità" richiamato dall'art. 8 § 2 C.e.d.u. esclude la legittimità in chiave convenzionale di un'indiscriminata schedatura "di massa" dei consociati ${ }^{49}$. Omettendo ogni sforzo di assicurare un accettabile contemperamento degli interessi in conflitto, difficilmente supererebbe lo scrutinio dei giudici di Strasburgo la pretesa legislativa di includere nell'archivio genetico anche i profili di soggetti rispetto ai quali non possa formularsi alcuna prognosi sufficientemente plausibile di pericolosità sociale ${ }^{50}$. A ben poco varrebbe l'argomento secondo cui tanto più è consistente la quantità di informazioni genetiche a disposizione degli inquirenti, tanto più risultano elevate le probabilità di ricostruire la paternità delle tracce biologiche rilasciate nelle azioni criminose e, quindi, rafforzate le chance di prevenzione e di repressione dei reati. Al canone di "necessità" imposto dall'art. 8 C.e.d.u. è connaturata l'esigenza di una selezione dei soggetti da iscrivere nell'“anagrafe genetica", che il legislatore deve impegnarsi a soddisfare secondo parametri di ragionevolezza e di proporzionalità ${ }^{51}$.

Nell'ordinamento italiano il delicato compito di tracciare lo spartiacque è affidato all'art. 9 legge n. 85 del 2009, che assoggetta a prelievo di campione - da cui estrarre il profilo destinato ad alimentare

$49 \mathrm{Di}$ «un'archiviazione generalizzata dei profili genetici di tutta la popolazione, indipendentemente dal coinvolgimento in un procedimento penale», analizzano vantaggi, problematiche implicazioni e ostacoli normativi DAL MIGLIO, Chiara, GENTILOMO, Andrea, PICCININI Andrea, D’AURIA, Luca, Dal prelievo coattivo alla banca dati dei profili genetici: l'ennesima incompiuta, cit., p. 85. Individuano come prima contropartita di una banca dati a vocazione universale «the high economic cost involved» GUILLÉN, Margarina, LAREU, Marìa Victoria, PESTONI Carmela, SALAS, Antonio, CARRACEDO, Angel, Ethical-legal problems of DNA databases in criminal investigation, in Journal of Medical Etichs, 2000, f. 26, p. 267.

Difficile da giustificare anche la necessità di sottoporli al prelievo del campione biologico da cui estrarre il profilo, eventualmente vincendone la resistenza con la forza.

51 Un'esigenza analoga emergeva dalla Risoluzione del Consiglio del 9 giugno 1997 sullo scambio di risultati di analisi del DNA, là dove si affidava agli Stati membri dell'U.E. il compito di «stabilire a quali condizioni e per quali reati i risultati di analisi del DNA» possano «essere memorizzati in una banca dati nazionale». 
la banca dati del dna - un'ampia gamma di soggetti: detenuti, condannati ammessi a una misura alternativa alla detenzione a seguito di sentenza irrevocabile, soggetti arrestati in flagranza di reato o sottoposti a fermo, destinatari di una misura custodiale (custodia cautelare in carcere, arresti domiciliari) e di una misura di sicurezza detentiva applicata in via provvisoria o definitiva. L'occasione "normativa" del prelievo funzionale ad alimentare il database è rappresentata, pertanto, da «un pregresso incidente giudiziario ${ }^{52}$, dal quale sia derivata una limitazione della libertà personale.

Non tutte le ipotesi di restrizione dello status libertatis alle quali il legislatore ha associato l'asportazione del campione presuppongono, oltre alla accertata o presunta responsabilità per un reato, anche una specifica valutazione della propensione dell'interessato a commettere illeciti penali ${ }^{53}$. In generale, la legge n. 85 del 2009 pare ritenere condizione sufficiente all'ingresso del profilo di un certo soggetto nella banca dati del dna che la responsabilità penale del medesimo sia stata accertata definitivamente oppure ipotizzata sulla base di elementi (i gravi indizi di colpevolezza, lo stato di flagranza) abbastanza solidi da aver superato il vaglio di un organo giurisdizionale (il giudice che ha applicato la custodia cautelare in carcere o gli arresti domiciliari, quello che ha convalidato l'arresto o il fermo). A ben vedere, nella prospettiva del legislatore meno pacificamente secondo la dottrina - tanto l'accertamento definitivo della responsabilità penale ${ }^{54}$ quanto la prefigurabilità di quest'ultima

52 LEO, Guglielmo, Il prelievo coattivo di materiale biologico nel processo penale e l'istituzione della Banca dati nazionale del DNA, in Riv. it. med. leg., 2011, p. 972.

53 Tale valutazione ricorre, ad esempio, rispetto alle misure di sicurezza detentive applicate in via provvisoria o definitiva, alla custodia cautelare in carcere e agli arresti domiciliari disposti ai sensi dell'art. 274 comma 1 lett. c) c.p.p., all'arresto in flagranza giustificato dalla «pericolosità del soggetto desunta dalla sua personalità o dalle circostanze del fatto» ex art. 381 comma 4 c.p.p., idoneo a legittimare il prelievo purché sia stato convalidato.

54 Affermano che «la prognosi di coinvolgimento in futuri procedimenti finisce per ridimensionare anche la presunzione di innocenza» ORLANDI, Renzo, PAPPALARDO, Giuseppe, L'indagine genetica nel processo penale germanico. Osservazioni su una recente riforma, cit., p. 768, in quanto «una persona è resa osservabile, grazie all'impronta genetica, per il suo modo d'essere, desunto essenzialmente dalla sua storia giudiziaria; vale a dire in ragione di una 
sulla base di robusti indizi ${ }^{55}$ integrano un «elemento prognostico (...) circa la futura commissione di reati» ${ }^{56}$ in grado di giustificare sul piano funzionale l'acquisizione del profilo del soggetto in questione nel database rappresentativo dell'«attuale e/o probabile comunità criminale» ${ }^{57}$.

A delimitare l'estensione dell'archivio provvede l'art. 9 comma 2 legge n. 85 del 2009: l'operazione di prelievo è consentita soltanto se il reato per cui si procede o si è proceduto rientra nel novero dei delitti non colposi per i quali è consentito l'arresto (almeno) facoltativo in flagranza. Letta in collegamento con la prognosi di pericolosità implicita nell'affermazione, definitiva o provvisoria, della colpevolezza, la scelta legislativa di circoscrivere il "censimento genetico" ai soggetti riconosciuti definitivamente responsabili o fortemente indiziati della commissione di un reato di gravità medio-alta pare esprimere una possibile traduzione

pericolosità presunta che lascia già intuire il coinvolgimento della persona stessa in prossime attività criminose».

55 Non condivide che la presunzione di pericolosità sociale formulata per i condannati venga estesa a chi è sottoposto a restrizione della libertà personale a titolo cautelare GALLUCCIO MEZIO, Gaetano, Il prelievo di materiale biologico dalla persona sottoposta a restrizione della libertà personale in una recente pronuncia della Corte Suprema degli Stati Uniti, in Cass. pen., 2014, p. 1895, in quanto, «implicando l'equiparazione della persona gravemente indiziata di un'ipotesi di reato al colpevole, pare inconciliabile con la presunzione di innocenza riconosciuta all'imputato». Contra, GATTI, Emilio, La Banca dati nazionale del Dna e la salvaguardia del diritto al rispetto della vita privata del singolo, in Quest. giust., 6 giugno 2018, secondo cui l'osservanza dell'art. 27 comma 2 Cost. è assicurata dalla cancellazione dei dati a seguito di assoluzione definitiva. Il Portogallo aveva inizialmente riservato l'ingresso in banca dati ai soli dati genetici dei soggetti condannati a una pena non inferiore a tre anni di reclusione. Con legge n. 90 del 2017, ha rivisto in senso estensivo la disciplina, ammettendo l'ingresso dei profili dei soggetti sospettati; in argomento v. SCAFFARDI, Lucia, Giustizia genetica e tutela della persona, cit., p. 149.

56 LEO, Guglielmo, Il prelievo coattivo di materiale biologico nel processo penale e l'istituzione della Banca dati nazionale del DNA, cit., p. 972.

57 L'espressione è di GENNARI, Giuseppe, Bioinformazione e indagini penali: la l. n. 85 del 30 giugno 2009, cit., p. 2634. Le categorie soggettive richiamate dall'art. 9 legge n. 85 del 2009 sono portatrici «per espressa presunzione normativa di una pericolosità qualificata - e lato sensu seriale - tale da giustificarne, anche per le caratteristiche criminologiche del reato espressivo, la profilazione e l'archiviazione del profilo genetico», ritiene ALVINO, Francesco, La banca dati nazionale del DNA, in ALVINO, Francesco, PRETTI, Davide, Le indagini preliminari, Giappichelli, 2017, p. 349. 
del principio di proporzionalità insito nel riferimento alla necessità per esigenze preventive e di sicurezza contenuto nell'art. 8 \& 2 C.e.d.u., come interpretato dalla Corte europea dei diritti dell'uomo ${ }^{58}$ : il sacrificio che la conservazione del dato genetico in sé arreca alla informational privacy può dirsi legittimo solo nella prospettiva di prevenire la commissione o di consentire l'accertamento di fatti delittuosi che offendono beni giuridici di non trascurabile rilevanza ${ }^{59}$.

Il legislatore italiano si dimostra cosciente, però, che una selezione dei profili da immettere nella banca dati del dna esclusivamente affidata al criterio della restrizione della libertà personale in riferimento a reati per cui è ammesso l'arresto in flagranza può non bastare ad impedire incursioni ingiustificate nella sfera della riservatezza genetica. Sono perciò sottratti al prelievo di campione biologico i soggetti accusati o condannati per una serie articolata di reati, il cui comune denominatore sembra essere la circostanza che alla condotta criminosa non si accompagna alcun rilascio di tracce biologiche. Al di là delle

58 Nella sentenza Corte eur. dir. uomo, 4 dicembre 2008, S. e Marper c. Regno Unito, i giudici di Strasburgo si dicevano sorpresi dal carattere generale e indifferenziato con cui la legislazione inglese consentiva l'archiviazione dei dati genetici, sottolineando criticamente come la conservazione potesse essere disposta indipendentemente dalla natura e dalla gravità del reato di cui è sospettata la persona interessata nonché dall'età di quest'ultima. L'art. 9 legge n. 85 del 2009 valorizza in chiave selettiva natura e gravità del reato, ma non la minore età del soggetto passivo. La condizione anagrafica non è presa in considerazione neppure in riferimento a specifiche modalità operative di prelievo: il regolamento di attuazione si limita ad affermare che ad esso provvede, «sia per i soggetti minorenni che per gli adulti, il personale di Polizia penitenziaria, specificamente formato e addestrato», o, nei casi elencati dall'art. 5 comma 3, «il personale della forza di polizia delegata all'esecuzione del provvedimento restrittivo».

59 Una soluzione di questo tipo era auspicata anche dal Garante per la protezione dei dati personali: «nel caso in cui il Parlamento ritenesse di prevedere che, in aggiunta ad una banca dati alimentata da informazioni raccolte per esigenze investigative nel corso dei procedimenti penali, alcune categorie di soggetti (quali fermati, arrestati, indagati, imputati o condannati per determinati reati) debbano essere sottoposti in ogni caso a un prelievo obbligatorio di cui va chiarita la specifica finalità, occorrerebbe comunque individuare in maniera selettiva e proporzionata i soggetti interessati e i relativi reati che non potrebbero che essere definiti sulla base della loro particolare gravità» (Segnalazione al Parlamento e al Governo sulla disciplina delle banche dati del Dna a fini di giustizia, 19 settembre 2007). 
valutazioni che potrebbero formularsi circa l'esaustività dell'elencazione normativa, l'idea di fondo è che, se l'archiviazione del dato genetico in banca dati deve servire a far emergere eventuali recidive, conservare i profili dei soggetti accusati o condannati per determinati reati (ad esempio, reati tributari, fallimentari, in materia di intermediazione finanziaria, societari, contro la fede pubblica) non apporterebbe vantaggi in chiave preventiva o probatoria e, dunque, costituirebbe ingerenza non necessaria nella prospettiva dell'art. 8 C.e.d.u. ${ }^{60}$.

\section{Le CAUtele dA ADotTARe Nella fase di PRELIEVo}

Un legislatore consapevole non può limitarsi a disciplinare nell'an il prelievo di materiale biologico; regolamentarne il quomodo è essenziale al duplice fine di garantire l'attendibilità delle informazioni destinate alla banca dati e di impedire che l'asportazione del campione si traduca in una operazione lesiva dei diritti individuali.

In relazione al primo obiettivo, mentre nel 2009 l'attenzione legislativa si è concentrata sulla fase successiva al prelievo, limitandosi a raccomandare l'immediato invio del campione biologico al laboratorio centrale tenuto a provvedere alla tipizzazione del profilo, il successivo regolamento di attuazione ha circondato di cautele dettagliate e "tecnologicamente avanzate" anche l'asportazione della mucosa del cavo orale e la catena di custodia: si prescrive che l'interessato venga preliminarmente identificato mediante il sistema AFIS relativo alle impronte digitali, si impone al personale incaricato del prelievo l'adozione di dispositivi di protezione individuale, si definiscono modalità di

${ }^{60}$ Per una interessante presa di posizione contro gli automatismi che trascurano l'aspetto qualitativo v. il Parere della Commissione nazionale per la protezione dei dati nazionali portoghese, Paracer n. 18/2007, in SCAFFARDI, Lucia, Giustizia genetica e tutela della persona, cit., p. 141: l'obbligo di essere sottoposto a prelievo biologico «solo per il fatto di essere stato condannato a più di tre anni di reclusione, indipendentemente dalla rilevanza del DNA per la fattispecie criminosa posta in essere», integra «un automatismo cieco rispetto al principio di proporzionalità, basato sulla formazione di un profilo criminogeno della personalità dell'imputato». 
conservazione e di trasmissione al laboratorio centrale in grado di garantire l'integrità e la tracciabilità del campione ${ }^{61}$.

Dal secondo punto di vista, l'art. 9 comma 4 legge n. 85 del 2009 non appare felicemente formulato: a rigore, richiamando il «prelievo di mucosa del cavo orale», allude all'asportazione del tessuto epiteliale che riveste la superficie interna della bocca. Nondimeno, le indicazioni esecutive fornite dal regolamento attuativo supportano una lettura maggiormente in sintonia con il principio di minima offensività e con le raccomandazioni europee ${ }^{62}$, che riferisce l'asportazione alle «particelle di desquamazione della mucosa orale che si possono trovare nella saliva ${ }^{63}$ : il prescritto impiego di un tampone orale a secco «strofinato sulla parte interna della guancia ovvero sulle gengive per un tempo adeguato» sembra, infatti, tecnica conforme all'esecuzione del meno invasivo prelievo salivare.

Poco attenta ad individuare la tipologia di asportazione meno offensiva, la disciplina del 2009 raccomanda all'organo procedente - che il dato normativo vuole «specificamente formato e addestrato» - di operare nel «rispetto della dignità, del decoro e della riservatezza» dell'interessato ${ }^{64}$ e si sforza di dissuaderlo dal porre in essere comportamenti non ortodossi: oltre a imporgli di redigere un verbale delle operazioni effettuate, fa discendere dalla «violazione delle disposizioni previste dall'articolo 9»- espressione idonea a ricomprendere sia i casi di prelievo indebito, sia le ipotesi di asportazione gratuitamente offensiva - la distruzione del

61 Scopo, quest'ultimo, al quale risponde più in generale la procedura informatizzata riservata ai soli operatori autorizzati che assicura la gestione del flusso del campione biologico dalla fase dell'asportazione all'arrivo nella sede del laboratorio centrale (art. 5 comma 7 d.P.R. n. 87 del 2016).

62 L'esigenza di farsi carico delle possibili implicazioni del prelievo sulla sfera dei diritti individuali era affiorata già in sede europea: la Risoluzione del Consiglio del 9 giugno 1997 sullo scambio di risultati di analisi del DNA si preoccupava di assicurare che «la raccolta di materiale DNA ai fini della memorizzazione» fosse «corredata di garanzie per la protezione dell'integrità fisica» degli interessati. Sulla necessità che il prelievo di campioni biologici si realizzi con metodiche rispettose della dignità della persona e del suo diritto alla salute v. Corte eur. dir. uomo, 11 giugno 2006, Jalloh c. Germania, §§ 67 ss.

63 FELICIONI, Paola, Il regolamento di attuazione della Banca dati nazionale del dna: scienza e diritto si incontrano, cit., p. 731.

${ }_{64}$ Cfr. l'art. 9 commi 4 e 5 legge n. 85 del 2009. 
campione biologico e la cancellazione del profilo tipizzato, privando così le condotte contra legem di utilità investigativa ${ }^{65}$.

Difetta, tuttavia, una specifica attenzione normativa nei confronti dell'eventualità in cui il soggetto opponga resistenza al prelievo; un aspetto che un legislatore accorto non dovrebbe lasciare alla gestione, non di rado disinvolta, della prassi, dal momento che l'asportazione forzosa di un campione biologico - come affermato dalla Corte costituzionale rispetto al prelievo ematico coattivo - «non solo interessa la sfera della libertà personale, ma la travalica perché, seppure in minima misura, invade la sfera corporale della persona» ${ }^{66}$.

Interferendo con la libertà personale, nell'ordinamento italiano la disciplina dell'asportazione coattiva di materiale biologico deve collocarsi all'interno delle coordinate dell'art. 13 comma 2 Cost. Ebbene, mentre i casi e i modi dell'ablazione risultano sufficientemente definiti dall'art. 9 legge n. 85 del 2009, meno scontata è la capacità dell'attuale disciplina di soddisfare la necessità costituzionalmente imposta che il prelievo si fondi su un «atto motivato dell'autorità giudiziaria» ${ }^{67}$.

Anche quando si rende necessario vincere con la forza la resistenza dell'interessato all'asportazione, la disciplina prescinde discutibilmente dall'autorizzazione ad hoc dell'organo giurisdizionale; garanzia non surrogabile da «provvedimenti amministrativi motivati», i quali, «tenuto conto delle circostanze di fatto, diano atto delle ragioni che hanno reso necessaria la coercizione al fine di vincere la resistenza passiva del detenuto al prelievo» ${ }^{68}$. Il prelievo de quo non pare in alcun

65 Cfr., rispettivamente, gli artt. 9 comma 5 e 13 comma 3 legge n. 85 del 2009.

66 Così Corte cost., 9 luglio 1996, n. 238, dichiarando l'illegittimità costituzionale dell'art. 224 comma 2 c.p.p. «nella parte in cui consente che il giudice, nell'ambito delle operazioni peritali, disponga misure che comunque incidano sulla libertà personale dell'indagato o dell'imputato o di terzi, al di fuori di quelle specificamente previste nei "casi" e nei "modi" dalla legge».

67 Ritiene possa essere identificato nello «stesso atto impositivo della restrizione» della libertà personale, «tra i cui effetti lato sensu esecutivi si annovera ora, ex lege, l'identificazione genetica dell'interessato», ALVINO, Francesco, La banca dati nazionale del DNA, cit., p. 349, nota 19.

68 Cfr. invece la circolare D.a.p. del 26 ottobre 2016, avente a oggetto «Laboratorio centrale per la banca dati del DNA. Problematica inerente il prelievo coattivo del campione biologico del DNA in caso di rifiuto del ristretto». 
modo riconducibile alle «misure di trattamento rientranti nell'ambito di competenza» dell'amministrazione penitenziaria, eccezionalmente sottratte, secondo la giurisprudenza costituzionale ${ }^{69}$, all'osservanza delle garanzie di cui all'art. 13 Cost. perché «attinenti alle modalità concrete (...) di attuazione del regime carcerario in quanto tale, e dunque già potenzialmente ricomprese nel quantum di privazione della libertà personale conseguente allo stato di detenzione»; a ben vedere, il prelievo coattivo di campioni biologici comporta una limitazione della libertà personale aggiuntiva rispetto allo status detentionis e non funzionale a soddisfare «ragioni di ordine o di sicurezza» essenziali al suo mantenimento.

\section{I TEMPI DI CONSERVAZIONE: LE SCELTE NORMATIVE}

Nell'assetto delineato dalla legge n. 85 del 2009, a determinare la soppressione dei campioni biologici conservati nel laboratorio centrale e la cancellazione dei profili archiviati nella banca dati nazionale del dna sono ragioni processuali $\mathrm{o}$, in alternativa, fattori temporali. Nel primo caso, $\mathrm{i}$ predetti esiti conseguono all'irrevocabilità di una sentenza di assoluzione adottata perché il fatto non sussiste, l'imputato non lo ha commesso, il fatto non costituisce reato o il fatto non è previsto dalla legge come reato ${ }^{70}$.

69 Corte cost., 22 novembre 2000, n. 526.

70 Considerata l'attenzione peculiare riservata dalla Corte di Strasburgo all'esigenza che i minori nei cui confronti non sia stata emessa una sentenza di condanna «siano protetti da qualsiasi pregiudizio», in riferimento al «loro sviluppo e (alla) loro integrazione nella società», derivante dal fatto che «le autorità pubbliche, successivamente alla assoluzione, decidano di conservarne i dati personali (Corte eur. dir. uomo, 4 dicembre 2008, S. e Marper c. Regno Unito, § 124), in dottrina si ritiene che l'elenco delle formule da cui far derivare la cancellazione immediata dei dati relativi agli infradiciottenni debba comprendere, «per ridurre al minimo il pericolo di stigmatizzazione», anche «le sentenze di non luogo a procedere per irrilevanza del fatto, la concessione del perdono giudiziale, l'estinzione del reato per esito positivo della prova, la declaratoria di una causa di immaturità del minore, la declaratoria della non imputabilità per il minore di anni quattordici» (CAPITTA, Anna Maria, Conservazione dei DNA profiles e tutela europea dei diritti dell'uomo, in Arch. pen., 2013, n. 1, p. 30). 
Si tratta di una cancellazione «riabilitativa ${ }^{71}$, doverosamente associata dal legislatore alla definitiva smentita in sede giudiziale dell'ipotizzato collegamento tra il soggetto "schedato" e uno dei reati elencati dall'art. 9 legge n. 85 del 2009, che aveva rappresentato il presupposto della misura restrittiva della libertà personale a suo carico e del correlato prelievo del campione ${ }^{72}$.

In assenza di un'assoluzione definitiva con formula ampiamente liberatoria, l'eliminazione dei dati genetici dalla banca dati del dna e dal laboratorio centrale consegue al decorso di un periodo differentemente individuato a seconda della tipologia del dato. Il legislatore del 2009 si era limitato a individuare i termini massimi di conservazione ai quali il regolamento di attuazione avrebbe dovuto attenersi: per il campione biologico, venti anni dall'ultimo prelievo; per il profilo del dna, quaranta anni dall'ultima circostanza che ne ha determinato l'inserimento ${ }^{73}$.

Il d. lgs. n. 87 del 2016 pare aver tenuto conto delle perplessità dottrinarie circa la compatibilità di tali proiezioni temporali con il principio di proporzionalità ${ }^{74}$. Rispetto ai soggetti "schedati" nei cui confronti non è

71 La definizione è di FELICIONI, Paola, La prova del DNA nel procedimento penale, Giuffrè, 2018, p. 378.

72 La circostanza che la legislazione francese non prevedesse nel caso di assoluzione di un soggetto la cancellazione delle sue impronte digitali dallo schedario automatizzato in cui erano conservate è stata censurata per violazione dell'art. 8 C.e.d.u. da Corte eur. dir. uomo, 18 aprile 2013, M.K. c. Francia, in Dir. pen. proc., 2013, p. 809 ss. Per i possibili riflessi della decisione nel nostro ordinamento v. SCARCELLA, Alessio, Conservazione delle impronte digitali degli "assolti" e violazione dell'art. 8 Conv. e.d.u., in Dir. pen. proc., 2013, p. 823 ss.

73 In riferimento al range temporale individuato dalla legge n. 85 del $2009 \mathrm{v}$. D’AMATO, Antonio, La banca-dati nazionale del Dna e le modifiche al codice di procedura penale in tema di prelievi coattivi di materiale biologico a fini di prova, in Critica pen., 2009, p. 223: «il funzionamento della banca-dati nazionale è legata al fenomeno della recidiva: le possibilità che il profilo del DNA di un soggetto arrestato per un qualsivoglia reato sia riconosciuto corrispondente alle tracce di un altro reato aumentano in proporzione all'ampiezza del lasso temporale in cui tale confronto è possibile; al di sotto di un limite minimo l'archivio potrebbe risultare inutile (tenendo conto di un primo periodo in cui il soggetto resta detenuto)».

74 Per tutti, cfr. SANTOSUOSSO, Amedeo, COLUSSI, Ilaria Anna, La banca dati del DNA: questioni in tema di alimentazione, trattamento e accesso, presupposti, cancellazione e tempi di conservazione (artt. 5-15 l. n. 85/09), cit., p. 459; 
intervenuta un'assoluzione definitiva nel merito, il regolamento ha fissato il periodo di conservazione del campione nel laboratorio centrale in otto anni, che corrispondono alla sua fisiologica durata ${ }^{75}$; quanto al profilo genetico, ha introdotto un doppio binario temporale: la permanenza ordinaria all'interno della banca dati si protrae per trenta anni a partire dall'ultima registrazione ${ }^{76}$; diventa di quaranta anni quando il profilo archiviato appartiene a un soggetto dichiarato recidivo con sentenza definitiva - condizione che rafforza la prognosi di "pericolosità sociale" a suo carico, su cui si fonda di per sé l'acquisizione in banca dati del suo profilo genetico - o condannato con sentenza irrevocabile per reati di particolare gravità e natura ${ }^{77}$, in sintonia con i suggerimenti formulati dai giudici di Strasburgo ${ }^{78}$.

\section{7. ... E GLI ASPETTI DA RIMEDITARE}

A ben vedere, l'orizzonte trentennale di conservazione nella banca dati nazionale del dna riguarda i profili non soltanto dei condannati in via definitiva ma anche di coloro che, dopo essere stati ristretti nella libertà perché sospettati della commissione di un reato, siano destinatari di un

FANUELE, Chiara, Conservazione dei dati genetici e privacy: modelli stranieri e peculiarità italiane, cit., p. 129.

75 Più precisamente, ai sensi dell'art. 24 d.P.R. n. 87 del 2016, «il Dna estratto dai campioni biologici, dopo la sua completa tipizzazione deve essere distrutto» (comma 1), mentre «la parte del campione biologico non utilizzata ed il secondo campione di riserva sono conservati per un periodo di otto anni» (comma 3).

76 Condivide la scelta legislativa di abbreviare, rispetto alla soglia massima consentita dalla legge n. 85 del 2009, i termini di conservazione dei profili genetici FANUELE, Chiara, Il regolamento attuativo della banca dati nazionale del DNA: nuove garanzie e preesistenti vuoti di tutela, in Proc. pen. giust., 2017, p. 129 , ritenendola espressione di «un bilanciamento più efficace tra il diritto alla privacy e le esigenze di protezione della collettività».

77 Si tratta dei reati per i quali è previsto l'arresto obbligatorio in flagranza e dei reati ricompresi nel nutrito elenco dell'art. 407 comma 2 lett. a) c.p.p., in cui figurano, tra gli altri, il reato di associazione di tipo mafioso, il reato di tratta di persone, reati con finalità di terrorismo o di eversione costituzionale, reati in materia sessuale.

78 In questo senso v. Corte eur. dir. uomo, 22 giugno 2017, Aycaguer c. Francia, in Dir. proc. pen., 2017, p. 1389. 
provvedimento di archiviazione per infondatezza della notitia criminis o di una sentenza di non luogo a procedere con le formule il fatto non sussiste, l'imputato non lo ha commesso, il fatto non è previsto dalla legge come reato, il fatto non costituisce reato ${ }^{79}$.

Probabilmente sulla scelta di non associare a tali epiloghi del procedimento la distruzione del campione e l'eliminazione del profilo hanno inciso pragmatiche valutazioni "di economia": qualora sopravvenissero elementi in grado di determinare la riapertura delle indagini o la revoca della sentenza di non luogo a procedere, il procedimento penale riprenderebbe il suo corso e potrebbe concludersi con una sentenza di condanna a pena detentiva, che imporrebbe di effettuare nuovamente il prelievo del campione biologico e la tipizzazione del relativo profilo genetico, ove gli stessi fossero stati già soppressi ${ }^{80}$.

Pare tuttavia eccessivo che l'ordinamento si faccia carico a tal punto di tali esigenze, legate all'ipotetico verificarsi di circostanze neppure così frequenti, da omologare, sul piano della permanenza dei profili nella banca dati del dna, le due categorie soggettive appena richiamate ai condannati con sentenza irrevocabile ${ }^{81}$ : almeno quando un provvedimento giudiziale, ancorché non definitivo, abbia escluso i presupposti di merito per esercitare l'azione penale nei riguardi di un soggetto "schedato" o per trarlo a giudizio, il legislatore avrebbe dovuto, se non necessariamente

79 Secondo GENNARI, Giuseppe, Bioinformazione e indagini penali: la l. $n$. 85 del 30 giugno 2009, cit., p. 2636, in tal modo il legislatore considera «perenni sospetti coloro che hanno visto archiviare la indagine a loro carico e coloro che vengono prosciolti in udienza preliminare», compiendo una scelta «palesemente incostituzionale» e altresì «paradossale», in quanto l'indagato «da subito ritenuto non meritevole di un processo per carenza di elementi di accusa in grado di giustificare un dibattimento si trova ad avere un trattamento peggiore di chi riesce a dimostrare la propria innocenza solo dopo tre gradi di giudizio».

In senso critico rispetto alla soluzione legislativa v. anche SCAFFARDI, Lucia, Giustizia genetica e tutela della persona, cit., p. 245, secondo cui «il criterio di definitività del procedimento (...) non appare ragionevole e proporzionato rispetto al fine che si intende perseguire».

81 Introducendo così una difformità di trattamento - a parità di presupposti "proscioglitivi" - rispetto agli assolti in via definitiva che la differenza sul piano della "stabilità" del provvedimento tra archiviazione e sentenza di non luogo a procedere, da un lato, e assoluzione irrevocabile, dall'altro, potrebbe non essere sufficiente a giustificare. 
prevedere la soppressione immediata dei relativi profilo e campione, almeno stabilire una ingerenza "da conservazione" più circoscritta nel tempo ${ }^{82}$ rispetto a quella imposta a chi abbia visto accertata in via definitiva la propria responsabilità penale ${ }^{83}$.

L'opportunità di differenziare l'orizzonte temporale di conservazione pare trovare riscontro anche nella giurisprudenza della Corte europea dei diritti dell'uomo, che nel 2008 ha definito «particolarmente preoccupante (...) il rischio di stigmatizzazione che discende» dall'equiparazione, allora operata dalla legislazione inglese sul piano dei tempi di permanenza dei dati genetici nella banca dati del dna, tra i criminal suspects (soggetti «che non sono stati riconosciuti colpevoli di nessun reato») e i condannati ${ }^{84}$. È vero che in quel caso il comune trattamento prevedeva la conservazione a tempo indefinito dei dati immessi nel database, soluzione scartata dalla legge n. 85 del 2009. Tuttavia, anche considerando che il periodo di conservazione stabilito dal regolamento di attuazione risulta tutt'altro che trascurabile, tale accorgimento potrebbe non bastare a sottrarre la disciplina italiana alle censure dei giudici di Strasburgo, piuttosto attenti al rispetto dei canoni di ragionevolezza e proporzionalità quando si tratta di ingerenze legislative nella sfera privata e familiare.

\section{BIBLIOGRAFIA}

ALLEGREZZA, Silvia. Prova scientifica e dimensione europea, in CANZIO, Giovanni, LUPARIA, Luca (a cura di), Prova scientifica e processo penale, Milano: Giuffrè, 2018, p. 125 ss.

82 Ad esempio, l'ordinamento scozzese, accanto alla regola generale che impone la distruzione di campioni e profili relativi a soggetti non condannati, ha introdotto la possibilità eccezionale di conservare il profilo genetico di soggetti accusati ma non condannati per «specific relevant sexual or violent offences» per un periodo di tre anni, eventualmente prorogabile per altri due.

83 Soluzione preferibile secondo CAPITTA, Anna Maria, Conservazione dei DNA profiles e tutela europea dei diritti dell'uomo, cit., p. 29, a tutela del principio della presunzione di innocenza di cui all'art. 27 comma 2 Cost. e del diritto alla non stigmatizzazione, espressione del "giusto processo" di cui all'art. 111 comma 1 Cost.

${ }^{84}$ Corte eur. dir. uomo, 4 dicembre 2008, S. e Marper c. Regno Unito, § 122. 
ALVINO, Francesco. La banca dati nazionale del DNA, in ALVINO, Francesco, PRETTI, Davide, Le indagini preliminari, Torino: Giappichelli, 2017, p. 349 ss.

BIONDO, Renato. La Banca dati nazionale dna italiana, in Riv. it. med. leg., 2016, p. 213 ss.

CALIFANO, Licia. Il trattamento dei dati genetici: finalità di ricerca, esigenze di sicurezza e diritto alla protezione dei dati personali, in Cultura giuridica e diritto vivente, 2017, n. 4.

CAMON, Alberto. La disciplina delle indagini genetiche, in Cass. pen., 2014, p. 1426 ss.

CAPITTA, Anna Maria. Conservazione dei DNA profiles e tutela europea dei diritti dell'uomo, in Arch. pen., 2013, n. 1.

COCITO, Andrea. Parametri internazionali e affidabilità dei laboratori nelle analisi dei reperti e campioni, in MARAFIOTI, Luca, LUPARIA, Luca (a cura di), Banca dati del DNA e accertamento penale, Milano: Giuffrè, 2010, p. 91 ss.

COLAIACOVO, Cinzia. Competenza del Garante per la protezione dei dati personali sull'applicazione del Trattato di Prüm, in SCARCELLA, Alessio (a cura di), Prelievo del DNA e banca dati nazionale, Padova: Cedam, 2009, p. 189 ss.

COLOMBO, Eleonora. Il nuovo regolamento per l'istituzione della banca dati nazionale del dna: commento a prima lettura e confronto con le disposizioni di altri Stati UE, in Cass. pen., 2016, p. 4615 ss.

DAL MIGLIO, Chiara; GENTILOMO, Andrea; PICCININI Andrea; D'AURIA, Luca. Dal prelievo coattivo alla banca dati dei profili genetici: l'ennesima incompiuta, in Riv. it. dir. med. leg., 2007, p. 61 ss.

DEDRICKSON, Kristen. Universal DNA databases: a way to improve privacy?, in Journal of Law and the Biosciences, 2017, p. 647 ss.

FANUELE, Chiara. Conservazione dei dati genetici e privacy: modelli stranieri e peculiarità italiane, in Dir. pen. e proc., 2011, p. 129 ss.

FANUELE, Chiara. Il regolamento attuativo della banca dati nazionale del DNA: nuove garanzie e preesistenti vuoti di tutela, in Proc. pen. giust., 2017, p. 129 ss.

FASSONE, Elvio. Le scienze come ausilio nella ricerca del fatto e nel giudizio di valore, in DE CATALDO NEUBURGER, Luisa (a cura di), La prova scientifica nel processo penale, Padova: Cedam, 2007, p. 247 ss. 
FELICIONI, Paola. DNA e Banche dati europee, in AA. VV., Investigazioni e prove transnazionali, Milano: Giuffrè, 2017, p. 177 ss.

FELICIONI, Paola. Il regolamento di attuazione della Banca dati nazionale del dna: scienza e diritto si incontrano, in Dir. pen. proc., 2016, p. 712 ss.

FELICIONI, Paola. La prova del DNA nel procedimento penale, Milano: Giuffrè, 2018.

GALLUCCIO MEZIO, Gaetano. Il prelievo di materiale biologico dalla persona sottoposta a restrizione della libertà personale in una recente pronuncia della Corte Suprema degli Stati Uniti, in Cass. pen., 2014, p. 1895 ss.

GATTI, Emilio. La Banca dati nazionale del Dna e la salvaguardia del diritto al rispetto della vita privata del singolo, in Quest. giust., 6 giugno 2018.

GENNARI, Giuseppe. Bioinformazione e indagini penali: la l. n. 85 del 30 giugno 2009, in Resp. civ. e prev., 2009, p. 2630 ss.

GENNARI, Giuseppe. Genetica forense e codice della privacy: riflessioni su vecchie e nuove banche dati, in Resp. civ. e prev., 2011, p. 1184 ss.

GENNARI, Giuseppe. La istituzione della banca dati del Dna ad uso forense: dalla privacy alla sicurezza, in SCARCELLA, Alessio (a cura di), Prelievo del DNA e banca dati nazionale, Padova: Cedam, 2009, p. 71 ss.

GUILLÉN, Margarina. LAREU, Marìa Victoria, PESTONI Carmela, SALAS, Antonio, CARRACEDO, Angel, Ethical-legal problems of DNA databases in criminal investigation, in Journal of Medical Etichs, 2000, f. 26, p. 267 ss.

HAZEL, James; CLAYTON, Ellen; MALIN, Bradley; SLOBOGIN, Christopher. Is it time for a universal genetic forensic database?, in Science, 23 novembre 2018, p. 898 ss.

LAGO, Giampietro. Banche dati DNA: raccomandazioni internazionali, studio comparato con la Legge 85/2009, in Giust. pen., 2010, p. 142 ss.

LAGO, Giampietro. Il trattamento dei dati e dei campioni biologici: la banca dati nazionale del DNA e il bilanciamento tra le ragioni di giustizia e la tutela della privacy, in SCARCELLA, Alessio (a cura di), Prelievo del DNA e banca dati nazionale, Padova: Cedam, 2009, p. 120 ss.

LEO, Guglielmo. Il prelievo coattivo di materiale biologico nel processo penale e l'istituzione della Banca dati nazionale del DNA, in Riv. it. med. leg., 2011, p. 931 ss. 
LUPARIA, Luca. Dati genetici e cultura processuale: un futuro ancora da comporre, in MARAFIOTI, Luca, LUPARIA, Luca (a cura di), Banca dati del DNA e accertamento penale, Milano: Giuffrè, 2010, p. 348 ss.

MARAFIOTI, Luca. Le banche dati del dna. Una nuova frontiera investigativa nel trattato di Prüm, in MARAFIOTI, Luca-LUPARIA, Luca (a cura di), Banca dati del DNA e accertamento penale, Milano: Giuffrè, 2010, p. 8 ss.

MONTI, Andrea. Ambiguità semantiche, finalità dei trattamenti e limiti operativi della genetic evidence, in MARAFIOTI, Luca, LUPARIA, Luca (a cura di), Banca dati del DNA e accertamento penale, Milano: Giuffrè, 2010, p. 34 ss.

MONTI, Andrea. Conservazione dei campioni biologici e tutela dei diritti fondamentali della persona, in MARAFIOTI, Luca, LUPARIA, Luca (a cura di), Banca dati del DNA e accertamento penale, Milano: Giuffrè, 2010, p. 55 ss.

ORLANDI, Renzo. La riforma del processo penale fra correzioni strutturali e tutela "progressiva" dei diritti fondamentali, in Riv. it. dir. proc. pen., 2014, p. 1155 ss.

ORLANDI, Renzo; PAPPALARDO, Giuseppe. L'indagine genetica nel processo penale germanico. Osservazioni su una recente riforma, in Dir. proc. pen., 1999, p. 767 ss.

PRESUTTI, Adonella. L'acquisizione forzosa dei dati genetici tra adempimenti internazionali e impegni costituzionali, in Riv. it. dir. proc. e pen., 2010, p. 548 ss.

RICCI, Ugo; PREVIDERÈ, Carlo; FATTORINI, Paolo; CORRADI, Fabio. La prova del dna per la ricerca della verità, Milano: Giuffrè, 2006, p. 30 ss.

RICCI, Ugo. Un lampo di consapevolezza nella normativa italiana: il DNA oltre la suggestione e il mito, in Dir. pen. proc., 2016, p. 743 ss.

RODOTÀ, Stefano. Difendere i cittadini dagli abusi della scienza, in La Repubblica, 6 gennaio 1999.

SALSI, Giancarlo. La Banca Dati del DNA. Indagini genetiche e problematiche giuridiche, Bologna: Clueb, 2012.

SANTOSUOSSO, Amedeo; COLUSSI, Ilaria Anna. La banca dati del DNA: questioni in tema di alimentazione, trattamento e accesso, presupposti, cancellazione e tempi di conservazione (artt. 5-15 l. n. 85/09), in Pol. dir., 2011, p. 457 ss.

SCAFFARDI, Lucia. Giustizia genetica e tutela della persona, Padova: Cedam, 2017. 
SCARCELLA, Alessio. Conservazione delle impronte digitali degli "assolti" e violazione dell'art. 8 Conv. e.d.u., in Dir. pen. proc., 2013, p. 823 ss.

SCOLLO, Giancarlo. La disciplina attuativa della banca dati del dna e del laboratorio centrale, in MARAFIOTI, Luca, LUPARIA, Luca (a cura di), Banca dati del DNA e accertamento penale, Milano: Giuffrè, 2010, p. 165 ss.

SELLAROLI, Valentina. Il “caso S. e Marper" e la Corte europea: il DNA e il bilanciamento tra opposte esigenze in una società democratica, in Leg. pen., 2009, p. 646 ss.

SIGNORATO, Silvia. Il trattamento dei dati personali per fini di prevenzione e repressione penale, in Riv. dir. proc., 2015, p. 1492 ss.

TONINI, Paolo. Accertamento del fatto e informazioni genetiche: un difficile bilanciamento, in Dir. pen. proc. - Speciale Banche dati, 2009, p. 3 ss.

TONINI, Paolo. Informazioni genetiche e processo penale ad un anno dalla legge, in Dir. pen. proc., 2010, p. 883 ss.

TONINI, Paolo. Manuale di procedura penale, Milano: Giuffrè, 2018.

\section{Informações adicionais e declarações dos autores (integridade científica)}

Declaração de conflito de interesses (conflict of interest declaration): a autora confirma que não há conflitos de interesse na realização das pesquisas expostas e na redação deste artigo.

Declaração de autoria e especificação das contribuições (declaration of authorship): todas e somente as pessoas que atendem os requisitos de autoria deste artigo estão listadas como autores; todos os coautores se responsabilizam integralmente por este trabalho em sua totalidade.

Declaração de ineditismo e originalidade (declaration of originality): a autora assegura que o texto aqui publicado não foi divulgado anteriormente em outro meio e que futura republicação somente se realizará com a indicação expressa da referência desta publicação original; também atesta que não há plágio de terceiros ou autoplágio. 


\section{Dados do processo editorial}

(http://www.ibraspp.com.br/revista/index.php/RBDPP/about/editorialPolicies)

- Recebido em: 10/7/2019

- Controle preliminar e verificação de plágio: 23/7/2019

- Avaliação 1: 7/10/2019

Equipe editorial envolvida

- Avaliação 2: 8/10/2019

- Editor-chefe: 1 (VGV)

- Editoras-associadas: 2 (CC e BC)

- Revisores: 2

- Decisão editorial preliminar: 8/9/2019

- Retorno rodada de correções: 17/10/2019

- Decisão editorial final: 17/10/2019

\section{COMO CITAR ESTE ARTIGO:}

GABRIELLI, Chiara. L'archiviazione dei dati genetici a fini di giustizia penale: gli interessi in gioco, le prescrizioni europee, le soluzioni adottate dal legislatore italiano. Revista Brasileira de Direito Processual Penal, Porto Alegre, vol. 5, n. 3, p. 1385-1420, set./dez. 2019. https://doi.org/10.22197/rbdpp.v5i3.258

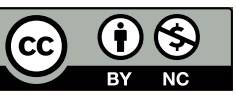

Esta obra está licenciada com uma Licença Creative Commons Atribuição-NãoComercial 4.0 Internacional. 